DOI 10.37882/2223-2982.2020.04.19

\title{
МЕНЕДЖМЕНТ АРТ-ИНДУСТРИЙ: КРОСС-ПОДХОД К СОЦИОКУЛЬТУРНОЙ КОНЦЕПЦИИ И ПРИБЫЛЬНОСТИ БИЗНЕСА
}

\section{ART MANAGEMENT: A CROSS-APPROACH TO THE SOCIO-CULTURAL CONCEPT AND BUSINESS PROFITABILITY}

\section{Rodionova Yu. Mindlin}

Summary: The article analyzes the features of management functioning in the sphere of culture and art. The specifics enable cross-approach between theory and practice of management (from the standpoint of the commercialization of art projects) and modern art (development of sense of beauty and education high feelings among fans). The author pays special attention to the analysis of the entrepreneurial aspect (a successful promotion can make even a very mediocre phenomenon an event, and Vice versa). The author justifies the need for specialists in the art sphere to use deep knowledge not only in the field of Economics and project management, but also in the field of the history of domestic and foreign culture, as well as a General high level of erudition and culture. Aesthetic education, extensive knowledge and appropriate education allow you to take into account not only financial, but also social results of your professional activities.

Keywords: art, art management, commercialization of art, socio-cultural space, social function of art.

\author{
Родионова Дарья Геннадьевна \\ Кандидат культурологии, Российская академия музыки \\ имени Гнесиных \\ sunshila@yandex.ru \\ Миндлин Юрий Борисович \\ К.э.н., дочент, Московская государственная академия \\ ветеринарной медицины и биотехнологии \\ имени им. К.И. Скрябина, \\ mindliny@mail.ru
}

Аннотация: В статье выполнен анализ особенностей функционирования менеджмента в сфере культуры и искусства. Рассмотрена специфика обеспечения кросс-подхода между теорией и практикой менеджмента (с позиции коммерциализации арт-проектов) и современным искусством (развитие чувства прекрасного и воспитание возвышенных чувств у почитателей). Особое внимание уделяется анализу предпринимательского аспекта (удачная промоакция позволяет сделать событием даже весьма посредственное явление и наоборот). Авторы обосновывают необходимость в деятельности специалистов арт-сферы использования глубоких знаний не только в области экономики и управления проектами, но и в области истории отечественной и зарубежной культуры, а также общего высокого уровня эрудиции и культуры. Эстетическое воспитание, обширные знания и соответствующее образование позволяют учитывать не только финансовые, но и социальные результаты своей профессиональной деятельности.

Ключевые слова: искусство, арт-менеджмент, коммерциализация искусства, социокультурное пространство, социальная функция искусства.

самореализации, желание изменить мир (талантливые художники способны не только исследовать концептуальное пространство, но и трансформировать его), и стремление славы, иногда даже толчком для творчества становятся разнообразные предельные состояния и устаревшие психосоматические травмы.

Конфликт имеет также и еще один аспект: далеко не всегда высокое, действительно высококачественное искусство находит своего зрителя, и наоборот, массовая культура в современном обществе, ориентированном, прежде всего, на потребление, довольно часто является лишь довольно низкопробным китчем, имеющим к искусству очень опосредованное отношение - превращает его в сугубо развлечение. Поэтому, главной проблемой функционирования менеджмента в сфере искусства, современные исследователи считают обеспечение единства между теорией и практикой менеджмента и современным искусством [12].

Кардинальные изменения в цивилизационных процессах, информационно-технологическая революция, 
мировые процессы глобализации и, как следствие, глубокие межкультурные изменения делают проблематику исследования менеджмента искусства чрезвычайно актуальной.

Несмотря на то, что проблематику менеджмента исследовало немало ученых: Ф. Хук [13], В. Стадник и М. Йохна [11], Е. Командышко [7] и др., вопрос определяющих особенностей функционирования менеджмента искусства требуют более детального освещения.

Заметим, что как невозможно точно назвать имя первого менеджера (ведь еще в самом начале исторического развития человечества управленцы давности реализовывали чрезвычайно смелые и масштабные креативные, организационные проекты), так и невозможно определить точную дату возникновения конфликта между созданием образцов высокого искусства и получением сугубо коммерческой прибыли от продажи массового продукта. Несомненно, уже первые менеджеры древних цивилизаций пытались решить для себя эту проблему. В частности, как отметили авторы книги «Реклама в памяти культур. Креатив древних цивилизаций»: «Египетская цивилизация была достаточно прагматичной и экономной, однако на осуществление масштабных градостроительных и художественных проектов она собирала и щедро тратила значительные материальные ресурсы» [10]. Итак, древние египтяне творили вечные памятники, можно сказать «создавали будущее», даже если в краткосрочной перспективе масштабные культурные проекты не только не обещали никаких прибылей, но и заставляли всю страну работать с полной отдачей, на грани экономического истощения. Впрочем, давние времена оставили также другие образцы художественного менеджмента. К примеру, в Древнем Риме художественные нормативные ценности были сформулированы предельно четко и однозначно: «хлеба и зрелищ». Соответственно, культурный продукт был превращен в инструмент политического влияния подчинение и манипулирование массами.

XX век стал периодом революционных изменений не только в области научно-технических революций, но и во взглядах на искусство. Так, если ранее критериями искусства были качество (красота) работы и мастерство (талант) мастера времена Возрождения добавили к этой классической формулы еще и право на субъективную интерпретацию представления о мире автора работы, то в современном мире, по меткому выражению Энди Уорхола, «каждый имеет право на 15 минут славы».

Разнообразные несложные вариации на темы обычных бытовых предметов, не только получили право быть провозглашенными высоким искусством, но и принести их создателям немалый доход. Соответственно, чрезвычайно возросла роль удачного менеджмента. Можно даже сказать, что именно благодаря продуманной рекламе потребитель воспринимает культурный продукт.
Например, можно вспомнить как в 1970-е годы Малькольму Макларену с помощью удачного менеджмента удалось не только создать жизнеспособный музыкальный коллектив из людей без всякой профессиональной образования или опыта, но и вызвать настоящую панкреволюцию и появление нового музыкального стиля.

Заметим, что сам Макларен в своей жизни перепробовал немало различных профессий, но так и не удосужился получить какое-либо системное образование. Однако, все его попытки, как в бизнесе, так и в искусстве заканчивались разгромными неудачами. Возможно, мир никогда и не узнал бы о существовании менеджера-самоучки, но «каждый имеет право на 15 минут славы».

Макларен стал спонсором, менеджером и главным идеологом не только группы Sex Pistols, но и всего нового рок-направления. Ведь все другие панк-группы, которые в огромном количестве создавались (и создаются под влиянием творчества Sex Pistols, лишь копировали их стиль, который мгновенно стал каноническим. Основой имиджа группы Макларен сделал сознательную провокацию, максимальный эпатаж, общественный вызов, что гарантировало широкий резонанс, острую полемику, а вместе с тем и бесплатную, но чрезвычайно действенную рекламу. К примеру, в год двадцатилетия вступления английской королевы на престол Sex Pistols записали песню "God Save the Queen" откровенно провокационного, даже оскорбительного для содержания королевы. 7 июня (в день празднования юбилея) Малькольм Макларен снял лодку, курсировавшую Темзой вблизи королевского дворца. На нем музыканты дали открытый концерт. С помощью мощной аппаратуры звук громко разносился по городу [2].

Уже за полчаса и Макларен, и музыканты были арестованы полицией. Альбомы с записями «Пистолетов» мгновенно стали дефицитом, каждый англичанин жаждал услышать скандальную песню. По количеству продаж сингл "God Save the Queen" занял первое место в Англии: всего за несколько недель продано более 150 тыс. пластинок. Если на первые концерты группы приходило только 35-40 зрителей, то уже через несколько месяцев желающих послушать, а главное увидеть творчество «Пистолетов» были тысячи.

Псевдомузыканты, которые не знали даже основ нотной грамоты, легко получали контракты на безумные как на то время суммы. Фирма EMI в 1976 году предложила группе контракт на сумму 40 тыс. фунтов, в следующем году фирма А\&М уже 150 тыс. фунтов [5]. В 2006 году группа была включена в американский Зал славы рок-н-ролла. Так, новаторский подход, смелый поиск новых форм, определенная революционность и сознательная провокационность творчества, на фоне общего анализа общественно-политического и экономического контекста, вкупе с определенной уникальностью и харизматичностью художников стали примером удачного менеджмента, за- 
логом долгой и успешной карьеры.

Впрочем, заметим, что не всем музыкантам нравилась сознательная и активная коммерциализация группы. Участники Sex Pistols стали «рабами провокаций», общество ожидало от них только постоянного скандала, Макларен действовал по принципу «чем хуже, тем лучше». Музыканты, не согласные с позицией своего менеджера, покидали группу, которая, согласно своей рекламной концепции, и не имела шансов превратиться в долговременный проект. Ярко вспыхнув, пережив череду громких скандалов, драк, арестов, самоубийство бас-гитариста Сида Вишеза, группа распалась.

Заметим, что в отличие от стран Запада, художники в СССР долгое время находились на обочине цивилизационных процессов. В стране царствовал соцреализм. Культурная жизнь была чрезвычайно развитой, но под абсолютным контролем государства. Новые формы могли развиваться лишь полуподпольно, постоянно балансируя на грани или запрета, или уголовного преследования. Менеджмент художника, ориентированный на финансовый успех, не имел права на существование, ведь легко трактовался как уголовное преступление - «спекуляция».

В конце 1980-х годов в СССР в период гласности и либерализации, радикально изменились представления о творце, зрителя, творчество и коммерцию. Неофициальные художники, непризнанные художники получили возможность не только свободно выставляться как в СССР, так и за рубежом, но и поняли, что искусство тоже может быть достаточно прибыльным. Творческие личности осознали, что создание культурного продукта может стать полем больших возможностей, а не только тотальных ограничений и рисков.

Столкновение с рынком требовало от художников коренным образом новых подходов к оценке своего творчества. Новые времена требовали переосмысления сущности искусства. Классическая формула менеджмента искусства, которая была сформулирована директором одного из немецких театров: «Мы делаем это ради удовольствия, а не денег (но для утешения мы нуждаемся в деньгах!» [3] стала актуальной и для жителей СССР. Можно сказать, что они наконец столкнулись с проблемой, которую менеджеры демократического мира решали на протяжении многих лет: сочетания коммерции и творчества.

Однако, времена принципиальных бунтарей, которые работали исключительно ради высокой идеи, демонстративно противопоставляя себя миру коммерции, отходили в прошлое. Искать любой смысл, двойных глубокий смысл, или какие-то зашифрованные послания, к примеру, в перформенсах 1990-х годов, в массе своей было бесполезно. Акции были направлены, прежде всего, на максимальную эпатажность, что в свою очередь гарантировало широкую огласку, и, соответственно, широкую рекламу. Фактиче- ски, искусство сознательно приносили в жертву коммерческому успеху.

В частности, подобным образом построил свою карьеру художник-акционист Олег Кулик. Безусловно, московская публика в 1990-х годах уже не находилась в том информационном вакууме, который был характерным для эпохи застоя или сталинизма. Именно в связи с тем, что шокировать тогдашнее общество уже не было столь легкой задачей, акционистам приходилось выбирать максимально провокационные, даже иногда непристойные формы. Именно так родился перформенс - человек-собака Олега Кулика. Смысл акции (впервые в ноябре 1994 года), в отличие от перформенсов времен СССР, состоял не в критике господствующей идеологии, борьбе за права человека или привлечении внимания к каким-то общественно-политическим проблем, а исключительно в самом шоу. Заметим, что «шоу» было довольно несложным: абсолютно голый мужчина на центральных улицах Москвы себя агрессивную собаку. Кулик громко лаял, бросался на людей, пытался покусать прохожих, искал на себе паразитов и тому подобное - демонстрировал максимально «собачью» поведение. Несмотря на тот факт, что «шоу» длилось всего около тридцати минут, общественный резонанс был бешеным - родилась новая «звезда». Мир узнал о существовании Олега Кулика.

Ради закрепления эффекта Кулик еще несколько раз организовывал аналогичные перформенсы, каждый из которых получал активное освещение в прессе и на телевидении. Про Кулика снимали документальные фильмы и писали статьи. Приобретая себе скандальную славу, Кулик позиционирует себя как художника. Фотографии перформенсов, картины «человека-собаки», экспозиционные проекты (которые эксплуатировали, прежде всего, темы обнаженного тела в сочетании со сценами насилия, с широким использованием животной тематики) были выставлены на десятках разнообразных выставок.

Присутствие скандального акциониста гарантировало широкую рекламу. Если же объемы продаж шли на спад, «человек-собака» вновь появлялась на публике. Был создан бренд максимально «модного» художника [5].

О. Кулик делал попытки выйти и на международный уровень, шокируя жителей различных европейских столиц. Впрочем, европейская терпимость и толерантность всегда имели свои четко определенные законодательством пределы. Так, когда «человек-собака» попытался выставить свои работы в Париже на выставке современного искусства FIAC, то ему было немедленно предъявлено обвинение сразу по нескольким статьям уголовного кодекса: порнография, пропаганда насилия, зоофилия и тому подобное. Впрочем, по искренним признаниям самого художника «этот скандал стал очень выгодным для меня. Часть работ была продана, даже находясь закрытой в сейфах выставки» [4]. 
Заметим, что фактически подобное «искусство» снова возвращает потребителей культурного продукта к Древнему Риму с его канонической формуле «хлеба и зрелищ». Однако, и в наше время немало мастеров в деле популяризации своего творчества идут путем наименьшего сопротивления, делая ставку на эпатажность и скандальность, часто на грани законности.

В связи с чем, бесспорно, нельзя не согласиться с выводом В. Алексеевского по чрезвычайно высокой ответственности менеджеров искусства: «Арт-менеджмент на современном этапе можно трактовать как своеобразную культуру руководства, присуща развитой гуманистической цивилизации, стремящейся глобализировать усилия человечества как ноосферное явление» [1]. Ведь именно менеджеры искусства в значительной степени ответственны за формирование вкусов и идеалов социума. Впрочем, как откровенно отметили в своей работе «Менеджмент» известные исследователи С. Робинс и М. Коултер: «добрые менеджеры могут превратить солому в золото» [9]. Именно поэтому менеджерам искусства стоит быть чрезвычайно осторожными, некритично применяя в своей практике законы и принципы «классического» менеджмента. Превращение «соломы в золото», когда нормы морали сознательно приносятся в жертву прибыльности того или иного проекта, может вызвать деградацию не только художественных норм, но и самого общества.

В учебном пособии «Технологии арт-менеджмента» то и дело неутомимо подчеркивается то, что одной из задач профессионального арт-менеджера является создание «звезды» (хорошо, что хоть беря это слово в кавычки) [8]. Заметим, что, действительно, качественная стратегия может сделать «звезду» практически из любого продукта, но если из всего спектра составляющих успеха выбирать только скандальную славу, провокацию, максимальный эпатаж, что должно приносить огласку и быстрые финансовые дивиденды, то на выходе получим коммерчески привлекательные, но сомнительные проекты, ведь вряд ли кто-то осмелится назвать перформансы Кулика «ноосферным явлением».

Именно поэтому на завершающем этапе художественного проекта необходимым условием является проведение экспертизы и анализа творческих, педагогических и финансовых результатов [8]. Ориентирование исключительно на факторе финансового успеха сужает использования всего спектра технологий художественного менеджмента, сводя все к примитивным манипуляциям общественного мнения.

Итак, менеджмент искусства имеет свои особенности, отличающие его от классического менеджмента. В частности деятельность специалистов данной сферы требует глубоких знаний не только в области экономической науки, но и наличия достаточной базы в истории отечественной и зарубежной культуры, а также общего высокого уровня эрудиции и культуры. Эстетическое воспитание, основательные знания и соответствующее образование позволяют учитывать не только финансовые, но и социальные результаты своей профессиональной деятельности. Ведь в современном мире искусство уже никак не может выступать сугубо развлекательным элементом (уровень «хлеба и зрелищ» более присущ рабовладельческом обществу), зато воспитательная функция искусства выступает мощным фактором, что обеспечивает развитие человечества в соответствии с принципами гуманистической цивилизации.

\section{ЛИТЕРАТУРА}

1. Алексеевский В.С. Социокультурная концепция общей теории менеджмента // Менеджмент в России и за рубежом. - 2004. — № 2. — C. $21-36$.

2. Грачев В.И. Коммуникативные культурфеномены и парадоксы современного российского арт-менеджмента // Вестник Московского государственного университета культуры и искусств. - 2006. - № 1. - С. 81-86.

3. Добрякова Е. Олег Кулик: «Я могу вызывать омерзение» // Невское время. — Режим доступа: https://nvspb.ru/2008/12/10/olegkulikyamoguvizivat-39480

4. Древс-Силла Г. Телесные опыты человека-собаки: «Собака Павлова» Олега Кулика // Русская литература и медицина: Тело, предписания, социальная практика: Сб. статей. / Под ред. К. Богданова, Ю. Мурашова, Р. Николози. — М.: Новое издательство, 2006. — С. 269-280.

5. Кокарев А. Панк-рок от А до Я. - М.: Музыка, 1992. - 80 с.

6. Колбер Ф. Арт-менеджмент — наука третьего тысячелетия / Ф. Колбер, И. Эврар // Арт-менеджмент. — 2002. — № 3. — C. 3-10.

7. Командышко Е.Ф. Арт-менеджмент в вопросах и ответах: учебно-методич. пособие. — М.: Военный университет, 2012.

8. Новикова Г.Н. Технологии арт-менеджмента: учебное пособие / Г. Н. Новикова. — М.: Изд. дом МГУКИ, 2006. — 178 с.

9. Роббинс С.П. Менеджмент / С.П. Роббинс, М. ; [пер. с англ. и ред. О. В. Медведь]. - 8-е изд. - Москва: Вильямс, 2007. - 1044 с.

10. Романова А. Появятся арт-менеджеры - заработает рынок // Художественный Совет. - 2009. - № 4. - С. 10-12.

11. Стадник В.В. Менеджмент / В.В. Стадник, М.А. Йохна. — К.: Академвидав, 2017. - 471 с.

12. Тульчинский Г.Л. Менеджмент в сфере культуры: учеб. пособие / Г. Л. Тульчинский, Е.Л. Шекова. — [2 изд., исправл. и доп.]. — СПб.: Лань, 2013. — 528 с.

13. Хук Ф. Завтрак у Sotheby's. Мир искусства от А до Я. - СПб.: Азбука, 2015. - 416 с. 